\title{
The Cardiopharyngeal Field in the Light of Evolutionary Medicine- Implications for Human Syndromes
}

\section{Ziermann JM*, Fahimuddin F, Forrester A and Singh S \\ Department of Anatomy, Howard University College of Medicine, USA}

*Corresponding author: Janine M. Ziermann, Department of Anatomy, Howard University College of Medicine, Washington, DC 20059, USA, Tel-202-660-8447; Email: jziermann@yahoo.de

\section{Review Article}

Volume 1 Issue 2

Received Date: June 26, 2017

Published Date: August 02, 2017

\section{Abstract}

Human syndromes are often complex and not easily explained by a single gene mutation. Syndromes have a mix of symptoms that result from a failure in complex developmental networks. An in-depth analysis of the development of the head and heart tissues has recently shown that the musculature, which constitute these distinct systems arise from a common pool of mesoderm progenitor cells within the cardiopharyngeal field (CPF). This CPF was shown to be present early in the evolutionary development of vertebrate embryos. Furthermore, analysis of the development of tunicates, chicken and mice lead to a better understanding of the evolution and development of head and heart muscles. This in turn has the potential to increase our understanding of syndromes in which mainly cranial and cardiac structures (in particular muscles) are involved. The application of the basic science of evolutionary biology to improve our understanding of health and disease is the basis of evolutionary medicine. This approach has already proven to be helpful in understanding the evolution of various medical phenomena, as for example the evolution of autoimmune diseases. At this moment, DiGeorge Syndrome is the only condition under investigation regarding the contributions of the CPF. However, with increased knowledge it should be possible to identify other human syndromes that relate to defects in this complex developmental network. Here, we review the current knowledge regarding the evolution of the cardiopharyngeal field and show how this knowledge contributes to the understanding of cardiopharyngeal syndromes in humans.

Keywords: Cardiopharyngeal field; Myocardium; Pharyngeal mesoderm; First heart field; Second heart field; Branchiomeric musculature

\section{Introduction}

Most human syndromes include a multitude of abnormalities, which are not easily explained by a single gene mutation. A syndrome is defined as "a group of signs and symptoms that occur together and characterize a particular abnormality" [1]. An observable mix of symptoms results usually from a failure in complex developmental networks. To understand the occurrence of abnormalities in human development the field of evolutionary medicine can make important contributions. 


\section{Evolutionary Medicine}

Evolutionary Medicine is an interdisciplinary field that combines knowledge gained from evolutionary biology, developmental biology, medicine, public health and other health professions [2]. The knowledge of evolution of developmental networks, anatomical structures, and physiology, among others, improves the understanding of research and practice in medicine and epidemiology [3]. There are currently several examples on how evolutionary medicine has been proven to be helpful in understanding the evolution of antibiotic resistance [4], cancer [5,6], autoimmune diseases [7], and other health related issues [for more examples see: 2,3,8]. In this review, we highlight the research on the cardiopharyngeal field and how the knowledge of the evolution and development of this field might contribute to our understanding on why many human syndromes often include craniofacial and cardiac anomalies.

\section{Cardiopharyngeal Field}

Muscles develop from mesodermal cells with a myogenic fate, which is determined early in embryonic development during mesodermal differentiation. Different mesodermal population give rise to different muscle groups dependent on signals from surrounding tissues and intrinsic activation of specific gene cascades. The myogenesis of head muscles differs fundamentally from trunk muscles [e.g., 9,10-15]. Based on clonal studies in mice, several mesodermal populations were identified that give rise to specific muscle groups of the head, neck, and heart, which will be the focus of this review (Figure 1) [16-18].

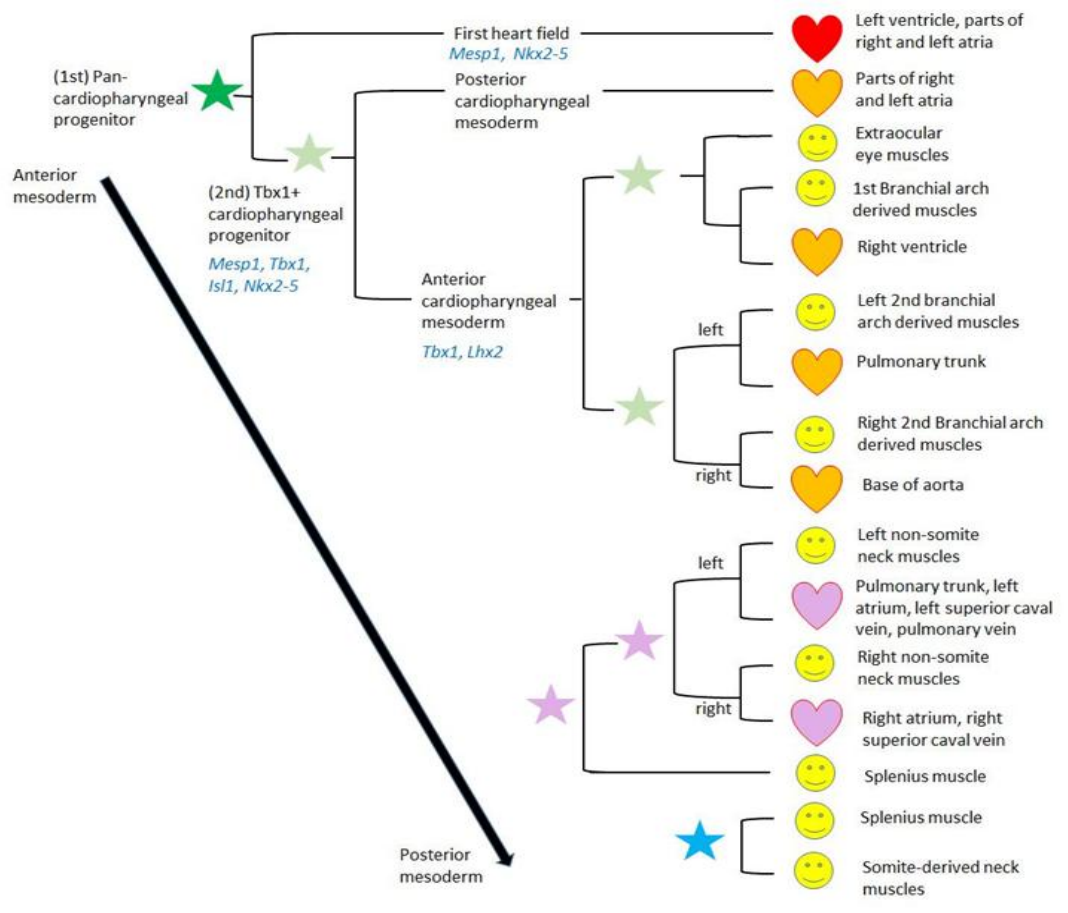

Figure 1: Proposed cell lineage tree in mice based on Lescroart et al. [16,18] and Diogo et al. [17].

Heads relate to cephalic (branchiomeric + somite derived head muscles) and hearts relate to myocardium derived from first heart field (red) and pharyngeal mesoderm (orange for 1st and 2nd pharyngeal arch mesoderm, purple more posterior pharyngeal arch mesoderm). Stars indicate common mesodermal progenitor cells. Dark green star is the pancardiopharyngeal progenitor of the cardiopharyngeal field, which gives rise to first heart field and pharyngeal mesoderm (light green star; Diogo et al. [17]). The latter includes the second heart field derived myocardium (orange hearts) and the branchiomeric mesoderm, which gives rise to muscles of the 1st and 2nd branchial arch (muscles of mastication, muscles of facial expression). Other mesodermal lineages also contribute to both cephalic neck and heart musculature, which correlate to posterior pharyngeal arch mesoderm (purple, probably $3^{\text {rd }}-6^{\text {th }}$ pharyngeal arch) and somite-derived mesodermal linages (blue star). The correlation of the latter two population to the cardiopharyngeal field has still to be elucidated. However, it is clear that they arise more posterior than the cardiopharyngeal mesodermal progenitors. Genes indicated in blue are essential markers for the specific mesodermal populations, however, the number of genes involved in CPF differentiation is by far great than shown here. 
During the past several years it has become clear that the head and heart muscle development underlie complex processes, which are more closely linked to each other than previously thought [e.g., 15,16,18,19,20-25]. Those insights were summarized and led to the concept of the cardiopharyngeal field (CPF) [17]. The CPF is an area that contains the anterior lateral mesoderm of the first heart field and the adjacent pharyngeal mesoderm that differentiates into the second heart field -derived regions of the heart and branchiomeric muscles [Figure 1; 17,26]. The vertebrate heart starts its development as a tube formed by a population of precursor cells called first heart field (FHF). The adjacent second heart field (SHF), located in the pharyngeal mesoderm, gives rise to cells that are gradually added to the forming heart [27]. Portions of the heart tube originating from the FHF progenitor cells later form the left ventricle and parts of the atria. The cells from the SHF differentiate to heart muscle tissue (myocardium) of the right ventricle, the main portion of the atria and the outflow tract $[19,20,28]$. The anterior populations of progenitor cells of the SHF contribute to the arterial pole of the heart and the posterior populations to the venous pole [29].

The pharyngeal mesoderm gives rise to either skeletal muscles, i.e. branchiomeric muscles, or cardiac muscle (SHF-derived regions) dependent on the signals upon adjacent tissues such as neural crest cells (NCCs), pharyngeal endoderm or surface ectoderm [e.g., 21,25,3032]. In turn, the cranial mesoderm is influencing NCC migration [33]. NCCs are crucial for the proper regulation of the CPF development: they control the arrangement of SHF-derived cells to the arterial pole of the heart, outline branchiomeric muscle patterns through neural crest derived mesenchyme, and give rise to the associated tendons and fascia [e.g., 31,34-36]. There are many syndromes that show a combination of cardiac and craniofacial malformations that can be related to NCCs $[37,38]$.

The cardiac and branchiomeric muscle development from the common pool of mesodermal progenitor cells is coordinated by regulatory factors [reviewed by 17]. Within the CPF is an overlapping expression of genes that specify head muscles [e.g. Tbx1, MyoR (Msc), Pitx2 and Tcf21 (Capsulin)] and cardiogenic regulatory factors [e.g., Nkx2-5, Isl1 (Islet1)] (Figure 1) [21,25,39,40]. Tbx1 plays a crucial role in extending the heart's arterial pole by stimulating proliferation and delaying differentiation of SHF cells [41 and citations within]. It is also important for the activation of branchiomeric myogenesis and may directly regulate MyoD [42,43]. Furthermore, Tbx1 acts upstream of $L h x 2$, a gene encoding a LIM- homeodomain protein, within a complex regulatory network that specifies cardiopharyngeal progenitors. Another gene encoding a LIM-homeodomain protein is Isl1, which is expressed in the mesoderm of pharyngeal arches and SHF. Ils1 seems to delay the differentiation of branchiomeric muscles; however, progenitor cells that express Isl1 contribute to heart and branchiomeric muscles, but not to extrinsic eye muscles or hypobranchial muscles $[25,40]$. This shows the important role of Isl1 as marker for a discrete subset of CPF cells that are distinct progenitors of cardiovascular and skeletal muscle [40]. Nkx2-5 is a cardiac transcription factor that regulates the proliferation in the SHF and it modulates, together with Isl1, SHF progenitor-specific gene expression $[44,45]$.

Clonal analyses in mice showed that SHF-derived regions of the heart are developmentally more closely related to branchiomeric muscles than to the FHF-derived regions of the heart $[17,18,26,46]$. This is supported by the observation that cardiac lineages contributing to the FHF and SHF diverge before the expression of Mesp1 during early gastrulation $[47,48]$. Based on those and other studies, the head muscles in humans can now be described as at least seven groups (Figure 2) [49]: 1. mandibular arch muscles and cells related to the right ventricle; 2 . left hyoid arch muscles and cells related to myocardium at the base of the pulmonary trunk; 3 . right hyoid arch muscles and cells related to myocardium at the base of the aorta; 4. left muscles of the 3rd to 6th pharyngeal arch, including laryngeal and pharyngeal muscles, the neck muscles trapezius and sternocleidomastoideus, and cells related to the base of the pulmonary trunk and part of left atrium; 5. right muscles of the 3rd to 6th pharyngeal arch, including laryngeal and pharyngeal muscles, the neck muscles trapezius and sternocleidomastoideus, and cells related to the superior vena cava and part of right atrium; 6 . extraocular muscles; and 7. Hypobranchial muscles, including tongue and infrahyoid muscles that derive from somites and migrate into the head and neck [16-18,5052]. 


\section{Journal of Human Anatomy}

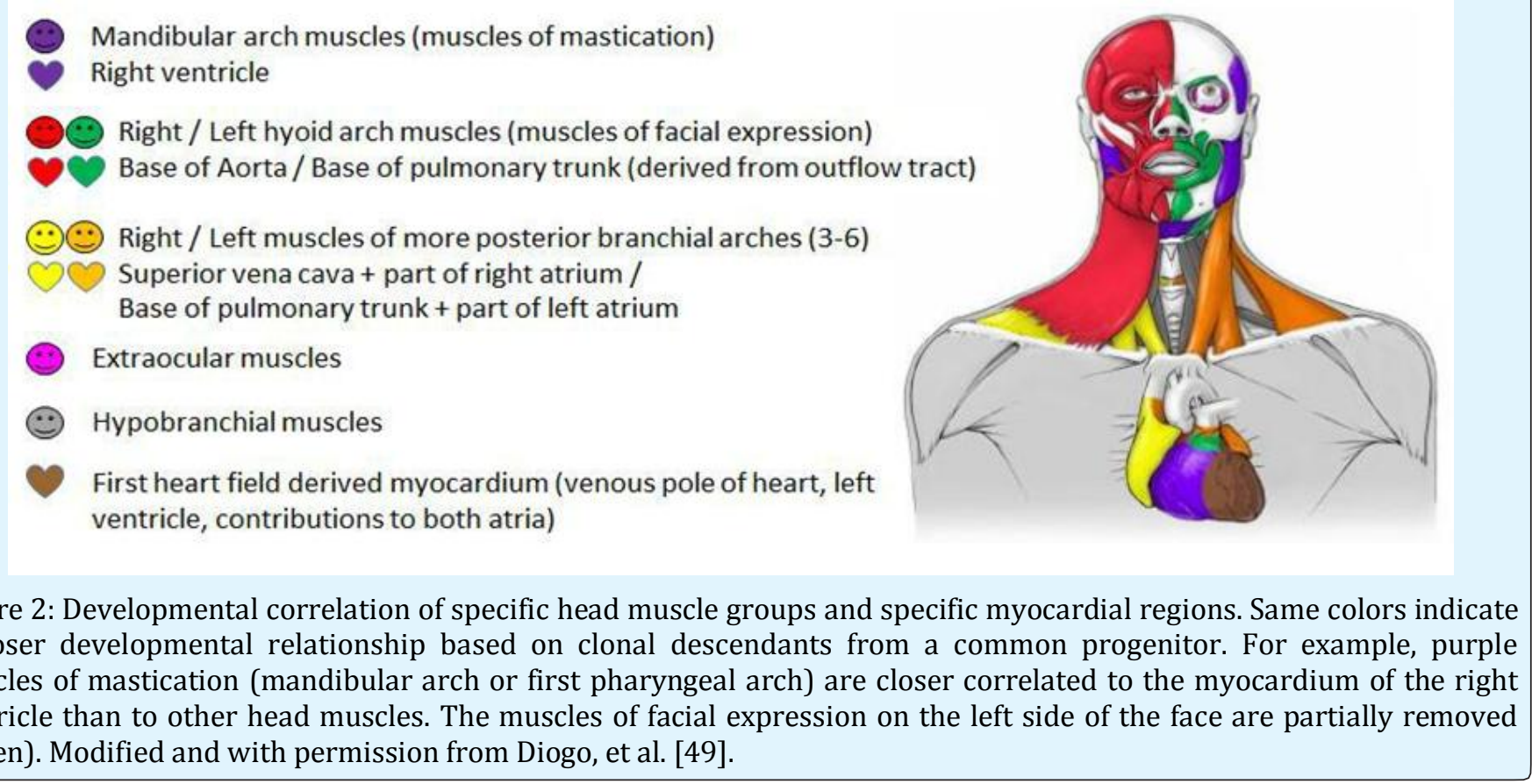

The FHF and SHF both have a common mesodermal progenitor [46], but the evolutionary origin of this common field was just recently discovered [17]. The closer correlation of cell lineages that give rise to branchiomeric muscles and myocardium were shown to also exist in the urochordate ascidian Ciona [53], and in the amniotes chicken and mice $[20,26,39,40,48]$. Urochordates are the closest sister-group of vertebrates [54]. Studies have shown that the gene regulatory network underlying the differentiation of pharyngeal muscles and myocardium in ascidians is similar to the one in vertebrates. The ascidian heart derives in early embryogenesis from two Mesp expressing cells (B7.5 cells), which give rise to four embryonic trunk ventral cells (TVCs) [55]. Those TVCs express genes homologous to the vertebrate genes $N k x 2-5$, Hand [55,56], Gata4, 5 and 6 [57] and migrate towards the pharyngeal endoderm [58-60]. This is followed by an asymmetrical division that produces heart precursors and secondary ventral cells. The latter cells divide again and give rise to second heart precursors and atrial siphon muscles; the latter correspond to branchiomeric muscles in vertebrates $[23,53,61]$. Thus, TVCs are cardiopharyngeal progenitors that produce cardiac and pharyngeal muscles, following a clonal pattern reminiscent of that seen in mice $[61,62]$.

Thus, the CPF likely evolved in the last common ancestor of Olfactores (Olfactores = Vertebrata + Urochordata) [17]; which emerged ca. 514 million years ago [63], but some of the mechanisms were likely present even earlier [17]. The knowledge regarding the evolution of the CPF and the gene regulatory network underlying the muscular differentiation had profound implications for the reconstruction of the origin and early evolution of the vertebrate muscular system [64]. Furthermore, understanding the molecular basis of craniofacial and heart development is an important research area, because malformation of both systems are among the most frequent congenital defects in humans [65].

\section{Cardiopharyngeal Syndromes}

Many human syndromes include both craniofacial and cardiac abnormalities. Syndromes that are likely caused by defects in the gene regulatory network underlying the mesodermal differentiation of the CPF are called cardiopharyngeal syndromes. Importantly, those syndromes will also show other malformations not related to the CPF as genes are usually not only expressed at one location during development. To our knowledge, only the DiGeorge Syndrome is currently under investigation regarding the contributions of the CPF. The DiGeorge Syndrome is a developmental defect caused by a microdeletion of chromosome 22q11.2. It is also known as velocardiofacial syndrome, CATCH22 [66], or 22q11 Deletion Syndrome (22q11DS) and has an estimated prevalence of 1 in 3,000-6,000 births, what makes it to one of the most common microdeletion syndromes [67]. The microdeletion of the chromosome 22q11.2 causes the 
compromise of the Tbx1 gene [68], which is important for the specification of the pharyngeal mesoderm [43] that gives rise to the SHF-derived myocardium and branchiomeric muscles (Figure 1). For the DiGeorge Syndrome over 180 associated anomalies have been described [69]. Those anomalies include often cardiac anomalies, palatal anomalies, developmental delay, and immune deficiency; not as common are feeding problems, renal anomalies, and psychiatric disorders, among others. However, none of these features are obligatory or present in all patients [69]. Due to the diversity of symptoms, the clinical diagnosis is usually confirmed by a routine test available in most cytogenetic laboratories [70].

To find other potential cardiopharyngeal syndromes, we performed an extensive search of syndromes that show a combination of cranial and cardiac muscle defects and analyzed if they are likely caused by developmental defects related to the differentiation from the CPF. We began our search by using a keyword search in Google Scholar. Initially we searched for the following keywords and combination of them: human; genetics; head muscles; heart muscle; heart; branchiomeric muscles; diseases; anomalies; syndrome; variations; face malformation; cardiovascular defects; craniofacial anomalies; face defect; heart defect; craniofacial muscle patterning; facial muscle deformation; craniofacial defect. One typical search combination was for example: "head + heart + malformation + human" or "head + heart + syndrome".

This search revealed thousands of results, and we identified many potentially interesting syndromes. From this list, we searched for specific syndromes and decided to take a closer look at syndromes with the most google scholar hits (Table 1). We refined the search by using the syndromes' common name(s) and restricted the search to the past ten years. In those ten years, we were looking for review article summarizing the knowledge so far and searched then for articles that are newer than the latest review. Finally, we restricted the search to the time since the publication of the CPF in 2015 [17] to determine of any syndromes were already under investigation regarding disturbances of the CPF differentiation.

\begin{tabular}{|c|c|c|c|}
\hline Syndrome & Google scholar & since 2007 & since 2015 \\
\hline Williams Syndrome & $2,800,000$ & $1,260,000$ & 38,400 \\
\hline Down Syndrome & $2,850,000$ & $1,340,000$ & 74,300 \\
\hline CHARGE Syndrome & $1,750,000$ & 416,000 & 20,100 \\
\hline Costello Syndrome & 86,100 & 23,800 & 13,400 \\
\hline Noonan Syndrome & 52,800 & 17,800 & 9,030 \\
\hline DiGeorge Syndrome & 30,000 & 16,000 & 4,360 \\
\hline 22q11 Syndrome & 34,700 & 16,800 & 6,700 \\
\hline DiGeorge + 22q11.2 Syndrome & 8,880 & 6,170 & 1,490 \\
\hline DiGeorge + cardiopharyngeal & 46 & 44 & 30 \\
\hline Fryns Syndrome & 23,700 & 11,800 & 2,300 \\
\hline Leopard Syndrome & 19,000 & 12,400 & 2,720 \\
\hline Ocular coloboma Syndrome & 17,500 & 8,950 & 2,250 \\
\hline Pierre-Robin Syndrome & 15,900 & 8,320 & 2,070 \\
\hline Alagille Syndrome & 15,400 & 7,490 & 1,990 \\
\hline Wolf Hirschhorn Syndrome & 9,120 & 5,750 & 1,330 \\
\hline Sotos Syndrome & 8,330 & 4,550 & 1,150 \\
\hline Holt-Oram Syndrome & 8,310 & 4,590 & 978 \\
\hline Microsomia Syndrome & 8,260 & 4,490 & 1,110 \\
\hline Ellis-van Creveld Syndrome & 6,060 & 3,380 & 680 \\
\hline 2q13 Syndrome & 5,860 & 3,800 & 828 \\
\hline
\end{tabular}




\section{Journal of Human Anatomy}

\begin{tabular}{|c|c|c|c|}
\hline 16q12 Syndrome & 4,250 & 3,020 & 644 \\
\hline Axenfeld-Rieger Syndrome & 3,260 & 2,210 & 527 \\
\hline Andersen-Tawil Syndrome & 1,820 & 1,540 & 394 \\
\hline 1q36 Syndrome & 402 & 290 & 66 \\
\hline Ritscher-Schinzel Syndrome & 371 & 266 & 62 \\
\hline Frank-Ter Haar Syndrome & 222 & 207 & 45 \\
\hline
\end{tabular}

Table 1: Human syndromes with craniofacial and cardiac abnormalities, which might be caused by defects in developmental processes related to the cardiopharyngeal field (CPF) mesoderm differentiation. DiGeorge syndrome is already under investigation regarding the connection of cranial and cardiac development (double underlined). The google search was latest updated July $16^{\text {th }}, 2017$. After searching for the syndromes with the most hits, we restricted our search for publications in the past 10 years to find most recent review articles and finally restricted the search to the time since the publication of the CPF in 2015 [17].

Most of the syndromes identified in Table 1 could not be related to the interruption of developmental mechanisms linked to the development cardiopharyngeal mesoderm. Furthermore, none of the investigated syndromes, including DiGeorge Syndrome, could be shown to show a left-right correlation of cranial muscle malformation and specific heart malformation as would be expected by the developmental disturbance of the CPF mesoderm. A review of all syndromes listed in Table 1 would by far exceed the purpose of this review; however, we highlight in Table 2 a few syndromes, additionally to the above mentioned DiGeorge Syndrome, that might be of interest for future research regarding cardiopharyngeal syndromes.

\begin{tabular}{|c|c|c|}
\hline Syndrome & Pathology & Mutation and relation to CPF development \\
\hline $\begin{array}{l}\text { Axenfeld - } \\
\text { Rieger } \\
\text { Syndrome }\end{array}$ & $\begin{array}{l}\text { Dysplastic arcade mitral valve; mildly } \\
\text { hypoplastic left ventricular outflow } \\
\text { tract and aortic arch; ophthalmologic } \\
\text { anterior segment abnormalities, } \\
\text { extraocular anomalies incl. dental } \\
\text { anomalies [71] }\end{array}$ & $\begin{array}{l}\text { autosomal dominant; involvement of PITX2, } \\
\text { FOXC1 (=Mf1) [71-73]; Pitx2 homeobox gene } \\
\text { regulates development of eye muscles, } \\
\text { branchiomeric muscles, tongue and laryngeal } \\
\text { muscles, and outflow tract [74, 75]; FoxC1 plays } \\
\text { an important role for the outflow tract and eye } \\
\text { muscle development }[76,77]\end{array}$ \\
\hline $\begin{array}{l}\text { Holt-Oram } \\
\text { syndrome }\end{array}$ & $\begin{array}{l}\text { upper limb defects ranging from } \\
\text { phocomelia to minor thumb } \\
\text { anomalies; cardiac defects in 50-95\% } \\
\text { of cases, most often an ostium } \\
\text { secundum type atrial septal defect } \\
\text { and conduction anomalies; [78] }\end{array}$ & $\begin{array}{l}\text { Mutation in TBX5 [78, 79], Tbx5 is essential in } \\
\text { cardiomyocyte differentiation in concert with } \\
\text { Nkx2-5 [79] }\end{array}$ \\
\hline $\begin{array}{l}\text { CHARGE } \\
\text { Syndrome }\end{array}$ & $\begin{array}{l}\text { complex mix of congenital anomalies, } \\
\text { including craniofacial structures, } \\
\text { tracheal development, peripheral } \\
\text { nervous system and some organ } \\
\text { systems, including the heart [80-83] }\end{array}$ & $\begin{array}{l}\text { autosomal dominant; heterozygous loss of } \\
\text { function mutation in CHD7 (see citations on the } \\
\text { left); CHD7 regulates genes, which are } \\
\text { important in neural crest guidance and is } \\
\text { important in the anterior mesoderm during } \\
\text { cardiovascular development [84,85] }\end{array}$ \\
\hline $\begin{array}{l}\text { Ocular } \\
\text { coloboma } \\
\text { Syndrome }\end{array}$ & $\begin{array}{l}\text { cardiac and eye abnormalities } \\
\text { including presence of ocular } \\
\text { colobomata [86] }\end{array}$ & $\begin{array}{l}\text { Oculo-auriculo-vertebral syndrome (OAVS) has } \\
\text { similar clinical presentations as CHARGE } \\
\text { Syndrome led to the assumption that here CHD7 } \\
\text { might be also [87]; see above for CHD7 }\end{array}$ \\
\hline
\end{tabular}

Table 2: Human syndromes that are potentially cardiopharyngeal syndromes based on the current knowledge of their gene mutations. 


\section{Journal of Human Anatomy}

\section{Concluding remarks}

Numerous genes are involved in the proper development of the head and the heart. The signaling from surrounding tissue, in particular the neural crest, has also a huge impact on the differentiation of cardiopharyngeal mesoderm. Here, we presented only a fraction of genes relevant for the differentiation of musculature derived from the CPF. Most of the knowledge we have about the gene regulatory networks during development result from studies in developmental biology, genetics, and evolutionary biology. The combination of those fields with medicine, public health, and other health professions leads to evolutionary medicine and to a better understanding of complex human syndromes.

\section{Acknowledgements}

JMZ was supported by a Howard University College of Medicine pilot study award (BFPSAP: U100217).

\section{References}

1. Merriam-Webster.com (2016) "Syndrome." MerriamWebster, n.d. Web. 1 May 2016.

2. Nesse RM, Williams GC (2012) Why we get sick: The new science of Darwinian medicine. Vintage.

3. Stearns SC (2012) Evolutionary medicine: its scope, interest and potential. Proc Biol Sci 279(1746): 43054321.

4. Davies J, Davies D (2010) Origins and evolution of antibiotic resistance. Microbiology Mol Bio Rev 74(3): 417-433.

5. Strassmann BI (1999) Menstrual cycling and breast cancer: an evolutionary perspective. J women's health 8(2): 193-202.

6. Zhu Y, Spitz MR, Amos CI, Lin J, Schabath MB, et al. (2004) An evolutionary perspective on singlenucleotide polymorphism screening in molecular cancer epidemiology. Cancer Res 64(6): 2251-2257.

7. Cho JH, Gregersen PK (2011) Genomics and the multifactorial nature of human autoimmune disease. N Engl J Med 365(17): 1612-1623.

8. Trevathan WR (2007) Evolutionary medicine. Annual Review of Anthropology 36: 139-154.
9. Noden DM, Francis-West P (2006) The differentiation and morphogenesis of craniofacial muscles. Dev Dyn 235(5): 1194-1218.

10. Sambasivan R, Kuratani S, Tajbakhsh S (2011) An eye on the head: the development and evolution of craniofacial muscles. Development 138(12): 24012415.

11. Harel I, Tzahor E (2013) Head Muscle Development, in Craniofacial Muscles. McLoon LK and Andrade FH, Editors. Springer New York. pp 11-28.

12. Buckingham M, Rigby PW (2014) Gene regulatory networks and transcriptional mechanisms that control myogenesis. Dev Cell 28(3): 225-238.

13. Czajkowski MT, Rassek C, Lenhard DC, Brohl D, Birchmeier C (2014) Divergent and conserved roles of Dll1 signaling in development of craniofacial and trunk muscle. Dev Biol 395: 307-16.

14. Bothe I, Tenin G, Oseni A, Dietrich S (2011) Dynamic control of head mesoderm patterning. Development 138(13): 2807-2821.

15. Michailovici I, Eigler T, Tzahor E (2015) Craniofacial Muscle Development. Curr Top Dev Biol 115: 3-30.

16. Lescroart F, Hamou W, Francou A, Théveniau-Ruissy M, Kelly RG, et al. (2015) Clonal analysis reveals a common origin between nonsomite-derived neck muscles and heart myocardium. Proc Natl Acad Sci USA 112(5): 1446-1451.

17. Diogo R, Kelly RG, Christiaen L, Levine M, Ziermann $J M$, et al. (2015) A new heart for a new head in vertebrate cardiopharyngeal evolution. Nature 520(7548): 466- 473.

18. Lescroart F, Kelly RG, Le Garrec J-F, Nicolas J-F, Meilhac SM, et al. (2010) Clonal analysis reveals common lineage relationships between head muscles and second heart fieldderivatives in the mouse embryo. Development 137(19): 3269-3279.

19. Waldo KL, Kumiski DH, Wallis KT, Stadt HA, Hutson $\mathrm{MR}$, et al. (2001) Conotruncal myocardium arises from a secondary heart field. Development 128(16): 3179-3188.

20. Kelly RG, Brown NA, Buckingham ME (2001) The arterial pole of the mouse heart forms from Fgf10 expressing cells in pharyngeal mesoderm. Dev Biol 1(3): 435-440. 
21. Tirosh-Finkel L, Elhanany H, Rinon A, Tzahor E (2006) Mesoderm progenitor cells of common origin contribute to the head musculature and the cardiac outflow tract. Development 133(10): 1943-1953.

22. Tzahor E (2009) Heart and craniofacial muscle development: a new developmental theme of distinct myogenic fields. Dev Biol 327(2): 273-279.

23. Stolfi A, Lowe EK, Racioppi C, Ristoratore F, Brown CT, et al. (2014) Divergent mechanisms regulate conserved cardiopharyngeal development and gene expression in distantly related ascidians. Elife 3: e03728.

24. Grifone R, Kelly RG (2007) Heartening news for head muscle development. Trends Genet 23(8): 365-369.

25. Nathan E, Monovich A, Tirosh-Finkel L, Harrelson Z, Rousso T, et al. (2008) The contribution of Islet1expressing splanchnic mesoderm cells to distinct branchiomeric muscles reveals significant heterogeneity in head muscle development. Development 135(4): 647-657.

26. Meilhac SM, Lescroart F, Blanpain C, Buckingham ME (2015) Cardiac cell lineages that form the heart. Cold Spring Harb Perspect Med 4(9): a013888.

27. Abu-Issa R, Kirby ML (2007) Heart field: from mesoderm to heart tube. Annu Rev Cell Dev Biol 23: 45-68.

28. Mjaatvedt C, Nakaoka T, Moreno-Rodriguez R, Norris R, Kern M, et al. (2001) The outflow tract of the heart is recruited from a novel heart-forming field. Dev Biol 238(1): 97-109.

29. Kelly RG (2012) The second heart field. Curr Top Dev Biol 100: 33-65.

30. Tzahor E, Lassar AB (2001) Wnt signals from the neural tube block ectopic cardiogenesis. Genes \& Development 15(3): 225-260.

31. Rinon A, Lazar S, Marshall H, Büchmann-Møller S, Neufeld A, et al. (2007) Cranial neural crest cells regulate head muscle patterning and differentiation during vertebrate embryogenesis. Development 134(17): 3065-3075.

32. Tzahor E and Evans SM (2011) Pharyngeal mesoderm development during embryogenesis: implications for both heart and head myogenesis. Cardiovasc Res 91(2): 196-202.
33. Fan X, Loebel DA, Bildsoe H, Wilkie EE, Qin J, et al. (2016) Tissue interactions, cell signaling and transcriptional control in the cranial mesoderm during craniofacial development.

34. Kirby ML, Waldo KL (1995) Neural crest and cardiovascular patterning. Circ Res 77(2): 211-215.

35. Hutson MR, Kirby ML (2003) Neural crest and cardiovascular development: a 20-year perspective. Birth Def Res C: Embryo today: Revs 69(1): 2-13.

36. Noden DM, Trainor PA (2005) Relations and interactions between cranial mesoderm and neural crest populations. J Anat 207(5): 575-601.

37. Kirby M (1988) Role of extracardiac factors in heart development. Experientia 44(11-12): 944-951.

38. Clouthier DE, Hosoda K, Richardson JA, Williams SC, Yanagisawa H, et al. (1998) Cranial and cardiac neural crest defects in endothelin-A receptor-deficient mice. Development, 125(5): 813-824.

39. Bothe I, Dietrich S (2006) The molecular setup of the avian head mesoderm and its implication for craniofacial myogenesis. Dev Dyn 235 (10): 28452860.

40. Harel I, Nathan E, Tirosh-Finkel L, Zigdon H, Guimaraes-Camboa N, et al. (2009) Distinct origins and genetic programs of head muscle satellite cells. Dev Cell 16(6): 822-832.

41. Rana MS, Théveniau-Ruissy M, De Bono C, Mesbah K, Francou A, et al. (2014) Tbx1 coordinates addition of posterior second heart field progenitor cells to the arterial and venous poles of the heart. Circ Res 115(9): 790-799.

42. Castellanos R, Xie Q Zheng D, Cvekl A, Morrow BE (2014) Mammalian TBX1 preferentially binds and regulates downstream targets via a tandem T-site repeat. PLoS One 9(5): e95151.

43. Kong P, Racedo SE, Macchiarulo S, Hu Z, Carpenter C, et al. (2014) Tbx1 is required autonomously for cell survival and fate in the pharyngeal core mesoderm to form the muscles of mastication. Hum mol genet 23(16): 4215-4231.

44. Prall OW, Menon MK, Solloway MJ, Watanabe Y, Zaffran S, et al. (2007) An Nkx2-5/Bmp2/Smad1 negative feedback loop controls heart progenitor specification and proliferation. Cell 128(5): 947-959. 


\section{Journal of Human Anatomy}

45. Watanabe Y, Zaffran S, Kuroiwa A, Higuchi H, Ogura T, et al. (2012) Fibroblast growth factor 10 gene regulation in the second heart field by Tbx1, Nkx2-5, and Islet1 reveals a genetic switch for downregulation in the myocardium. Proc Natl Acad Sci USA 109(45): 18273- 18280.

46. Meilhac SM, Esner M, Kelly RG, Nicolas JF, Buckingham ME (2004) The clonal origin of myocardial cells in different regions of the embryonic mouse heart. Dev Cell 6(5): 685-698.

47. Devine WP, Wythe JD, George M, Koshiba-Takeuchi K, Bruneau BG (2014) Early patterning and specification of cardiac progenitors in gastrulating mesoderm. Elife 3: e03848.

48. Lescroart F, Chabab S, Lin X, Rulands S, Paulissen C, et al. (2014) Early lineage restriction in temporally distinct populations of Mesp1 progenitors during mammalian heart development. Nat Cell Biol 16(9): 829-840.

49. Diogo R, Noden DM, Smith CM, Molnar J, Boughner JC, et al. (2016) Understanding Human Anatomy and Pathology: An Evolutionary and Developmental Guide for Medical Students. CRC Press. 330.

50. Edgeworth FH (1935) The Cranial Muscles of Vertebrates. London: Cambridge at the University Press.

51. Diogo R and Abdala V (2010) Muscles of Vertebrates Comparative Anatomy, Evolution, Homologies and Development. CRC Press; Science Publisher. 500.

52. Lescroart F, Mohun T, Meilhac SM, Bennett $\mathrm{M}$, Buckingham M (2012) Lineage tree for the venous pole of the heart clonal analysis clarifies controversial genealogy based on genetic tracing. Circ Res 111(10): 1313-1322.

53. Stolfi A, Gainous TB, Young JJ, Mori A, Levine M, et al. (2010) Early chordate origins of the vertebrate second heart field. Science 329(5991): 565-568.

54. Delsuc F, Brinkmann H, Chourrout D, Philippe H (2006) Tunicates and not cephalochordates are the closest living relatives of vertebrates. Nature 439: 965-968.

55. Satou Y, Imai KS, Satoh N (2004) The ascidian Mesp gene specifies heart precursor cells. Development 131(11): 2533-2541.
56. Davidson B, Levine M (2003) Evolutionary origins of the vertebrate heart: Specification of the cardiac lineage in Ciona intestinalis. Proc Natl Acad Sci USA 100(20): 11469-11473.

57. Ragkousi K, Beh J, Sweeney S, Starobinska E, Davidson B (2011) A single GATA factor plays discrete, lineage specific roles in ascidian heart development. Dev Biol 352(1): 154-163.

58. Davidson B, Shi W, Beh J, Christiaen L, Levine M (2006) FGF signaling delineates the cardiac progenitor field in the simple chordate, Ciona intestinalis. Genes Dev 20(19): 2728-2738.

59. Davidson B, Shi W, Levine M (2005) Uncoupling heart cell specification and migration in the simple chordate Ciona intestinalis. Development 132(21): 4811-4818.

60. Christiaen L, Davidson B, Kawashima T, Powell W, Nolla H, et al. (2008) The transcription/migration interface in heart precursors of Ciona intestinalis. Science 320(5881): 1349-1352.

61. Wang W, Razy-Krajka F, Siu E, Ketcham A, Christiaen L (2013) NK4 antagonizes Tbx1/10 to promote cardiac versus pharyngeal muscle fate in the ascidian second heart field. PLoS Biol 11(12): e1001725.

62. Razy-Krajka F, Lam K, Wang W, Stolfi A, Joly M, et al. (2014) Collier/OLF/EBF-dependent transcriptional dynamics control pharyngeal muscle specification from primed cardiopharyngeal progenitors. Dev Cell 29(3): 263-276.

63. Benton MJ, Donoghue PC, Asher RJ, Friedman M, Near TJ, et al. (2015) Constraints on the timescale of animal evolutionary history. Palaeontologia Electronica 18: 1-106.

64. Diogo R, Ziermann JM (2015) Development, metamorphosis, morphology, and diversity: The evolution of chordate muscles and the origin of vertebrates. Dev Dyn 244: 1046-1057.

65. CDC. Birth Defects: Data and Statistics. Centers for Disease Contol and Prevention - Birth Defects 2016 15 July 2017].

66. Wilson D, Burn J, Scambler P, Goodship J (1993) DiGeorge syndrome: part of CATCH 22. Journal of Medical Genetics 30(10): 852-856. 
67. Devriendt K, Fryns J-P, Mortier G, Van Thienen M, Keymolen K (1998) The annual incidence of DiGeorge/velocardiofacial syndrome. J Med Genet 35(9): 789-790.

68. Kelly RG, Jerome-Majewska LA, Papaioannou VE (2004) The del22q11.2 candidate gene Tbx1 regulates branchiomeric myogenesis. Human Molecular Genetics 13(22): 2829-2840.

69. Gothelf D, Frisch A, Michaelovsky E, Weizman A, Shprintzen RJ (2009) Velocardiofacial syndrome. Journal of mental health research in intellectual disabilities 2: 149-167.

70. Bassett AS, McDonald-McGinn DM, Devriendt $\mathrm{K}$, Digilio MC, Goldenberg P, et al. (2011) Practical guidelines for managing patients with 22q11. 2 deletion syndrome. J pediatr 159(2): 332-339. e1.

71. Gripp KW, Hopkins E, Jenny K, Thacker D, Salvin J (2013) Cardiac anomalies in Axenfeld- Rieger syndrome due to a novel FOXC1 mutation. Am J Med Genet A 161A(1): 114-119.

72. Tumer Z, Bach-Holm D (2009) Axenfeld-Rieger syndrome and spectrum of PITX2 and FOXC1 mutations. Eur J Hum Genet 17(12): 1527-1539.

73. Chang TC, Summers CG, Schimmenti LA, Grajewski AL (2012) Axenfeld-Rieger syndrome: new perspectives. Br J Ophthalmol 96(3): 318-22.

74. Dong F, Sun X, Liu W, Ai D, Klysik E, et al. (2006) Pitx2 promotes development of splanchnic mesodermderived branchiomeric muscle. Development 133(24): 4891-4899.

75. Harel I, Maezawa Y, Avraham R, Rinon A, Ma HY, et al. (2012) Pharyngeal mesoderm regulatory network controls cardiac and head muscle morphogenesis. Proc Natl Acad Sci USA 109(46): 18839-18844.

76. Seo S, Kume T (2006) Forkhead transcription factors, Foxc1 and Foxc2, are required for the morphogenesis of the cardiac outflow tract. Dev Biol 296(2): 421436.

77. Gage PJ, Rhoades W, Prucka SK, Hjalt T (2005) Fate maps of neural crest and mesoderm in the mammalian eye. Invest Ophthalmol Vis Sci 46(11): 4200-4208.
78. Lichiardopol C, Militaru C, Popescu B, Hila G, Mixich F (2007) Holt-Oram syndrome. Rom J Morphol Embryol 48: 67-70.

79. Hiroi Y, Kudoh S, Monzen K, Ikeda Y, Yazaki Y, et al. (2001) Tbx5 associates with $\mathrm{Nkx} 2-5$ and synergistically promotes cardiomyocyte differentiation. Nature genetics 28(3): 276-280.

80. Aramaki M, Udaka T, Kosaki R, Makita Y, Okamoto N, et al. (2006) Phenotypic spectrum of CHARGE syndrome with CHD7 mutations. The Journal of pediatrics 148(3): 410-414.

81. Jongmans M, Admiraal R, Van Der Donk K, Vissers L, Baas A, et al. (2006) CHARGE syndrome: the phenotypic spectrum of mutations in the CHD7 gene. J med genet 43(4): 306-314.

82. Lalani SR, Safiullah AM, Fernbach SD, Harutyunyan KG, Thaller C, et al. (2006) Spectrum of CHD7 mutations in 110 individuals with CHARGE syndrome and genotype phenotype correlation. Am J Hum Genet 78(2): 303-314.

83. Sperry ED, Hurd EA, Durham MA, Reamer EN, Stein $\mathrm{AB}$, et al. (2014) The chromatin remodeling protein CHD7, mutated in CHARGE syndrome, is necessary for proper craniofacial and tracheal development. Dev Dyn 243(9): 1055-1066.

84. Schulz Y, Wehner P, Opitz L, Salinas-Riester G, Bongers EM, et al. (2014) CHD7, the gene mutated in CHARGE syndrome, regulates genes involved in neural crest cell guidance. Hum genet 133(8): 9971009.

85. Payne S, Burney MJ, McCue K, Popal N, Davidson SM, et al. (2015) A critical role for the chromatin remodeller CHD7 in anterior mesoderm during cardiovascular development. Dev Biol 405(1): 82-95.

86. Ho C, Kaufman R, Podos S (1975) Ocular colobomata, cardiac defect, and other anomalies: a study of seven cases including two sibs. J med genet 12(3): 289-293.

87. Van Meter T, Weaver D (1996) Oculo-auriculovertebral spectrum and the CHARGE association: clinical evidence for a common pathogenetic mechanism. Clin Dysmorpho 5(3): 187-196. 